\title{
Política monetaria en centroamérica: Evolución reciente y perspectivas
}

\author{
Carlos J. Glower
}

\section{Introducción}

A raíz del grave deterioro económico que ha sufrido Centroamérica durante los últimos ocho años, la cobertura exigida a la política económica de cada pais ha cobrado una mayor vigencia y amplitud. Las naciones de la región han utilizado una plélora de instrumentos que van desde las medidas más convencionales hasta las menos ortodoxas, como son los tipos de cambio múltiple mixtos, etc. Empero, la bondad de los resultados está aún por determinarse.

En aras de obtener un mejor entendimiento de la variedad de políticas económicas actualmente aplicadas por los gobiernos centroamericanos, el presente documento prelende abarcar las medidas más imporlantes que se han tomado recientemente en la región y de esta forma oblener una mejor percepción sobre el electo que éstas han tenido en lo inlerno de cada pais.

El tema de la política monetaria en Centroamérica es demasiado importante para dejarlo en situación confusa, de modo que este trabajo podría ser considerado como un esluerzo más de aclaración sobre este amplio tema. Así, el entoque que se utiliza conjuga los aspeclos normativos con bs analíticos.

Consecuentemente, en la siguiente sección se establece el marco analítico, del cual se derivan algunos crilerios tradicionales para evaluar la efectividad de la polílica monetaria. En la segunda sección, se presentan, por pais, las medidas e instrumenlos que se han ulilizado, como también los objetivos que se persiguen; dentro de ese marco, se hace un conjunlo de apreciaciones relacionadas a las perspectivas que se vislumbran. En la última sección se hace una breve comparación para asi 
poder obtener un conjunto de generalizaciones sólidas.

\section{Marco analitico}

Por b general, la política monetaria pretende imprimir estabilidad a los vaivenes de una economia; en particular, ésta trata de normalizar los movimientos abruptos en los niveles de empleo y de precios, como tamblén alianzar la congnuencia que requiere cualquier desequilibrio entre la cuenta corriente y la cuenta de capital de la balanza de pagos.

Empero, cabe senalar que en algunos casos la política monetaria no es tan efectiva para lograr los objetivos antes mencionados. Ello es así por razones que incluyen aspectos institucionales, en el campo social, y estructurales que emanan del mismo diseno de la política monetaria que se quiere poner en práctlca.

Asl, un osbstáculo inslitucional to impone el hecho que en un pais donde no exista, o es incipiente un mercado financiero, los electos previstos de una politica monelaria dinámica y abrupla a la vez, pueden contribuir a que se obtengan resultados conlrarios a los esperados. No se debe de olvidar que el mercado financiero es el mecanismo de transmislón más importante de la politica monetaria. De esta forma, es teóricamente correcto aseverar que cuando un pals no posee un mercado tinanciero que incluya la transacción de recursos a largo plazo, la distinclón académica-formal entre la política monetaria y la política fiscal carece de sentido. En otras palabras, solamenle se puede hablar de politica económica en general.

Por su parte, los aspectos estructurales del disefio de la politica económica tamblén puede imponer otro tipo de obstáculos. Es un postulado de la teorla económica que la política monetaría es más eficiente en la medida en que el sistema cambiario sea más flexible. En particular, en el caso de un pals con un sistema cambiario flexible, se tiene casi una completa libertad para establecer el nivel de inflación que se desee. En el caso contrario -tipo de cambio tijo-, el componente más importante de la Inflación se origina en el exterior, por lo que se puede decir que existe una cierta validez cuando se habla de "inflación importada".

A pesar de lo anterior, el papel que puede jugar la políica monetaria en países como los centoamericanos no es tan árido." En las décadas de los sesenta y principio de los setenta, la política monelaria en la región centroamericana se caracterizo por su eliciencia en el campo de la estabilización de precios. Los niveles de inllación anual promedio de

- Para una mayor explicación véase Carlos J. Glower, "Polltica y control monetarios en Centroemérica", Monotarla, (Enero 1986): 1-54. C.E.M.L.A., México. 
Centroamérica en su conjunto se situaron por debajo del mismo indicador de Eslados Unidos. Considerando que este país fue el más importante consocio comercial y que los países de la región cenlroamericana mantuvieron un régimen cambiario fijo, era de esperar que la tasa inllacionaria centroamericana fuera levemente superior a la de esle país.

Asimismo, las medidas tomadas por las autoridades monelarias durante el período 1960-1977, fueron inequivocamente exitosas en el campo de las acciones compensatorias; particularmente, sobresalieron las medidas relacionadas a los embates de liquidez provenientes de sus respectivos sectores externos. En este campo, se destacaron Costa Rica y Nicaragua, ya que lograron neutralizar, como minimo, un $70 . \%$ de las variaciones originadas por la liquidez externa en la base monetaria. En menor grado, se descolla Honduras, con un $\mathbf{5 0 . 0 \%}$. Por su parte, Guatemala opló por una política que exigia que la base monetarla fuera determinada primordialmenle por la liquidez exlema, ya que en conladas ocasiones se utilizó el crédito interno como medida compensatoria. Sobre este aspecto, El Salvador no se colocó a la par de los demás palses; ya que la evidencia empírica no arroja resullados estadísticamenle confiables.

En lo tocante al objetivo final de la política monetaria de cada país duranle el mismo período, se puede afirmar que la prioridad de Guatemala, El Salvador y Nicargua fue la estabilidad económica, como se definió anteriormente; en forma un tanto ambigua se puede argumentar lo mismo para el caso de Honduras. En este campo, el caso de Costa Rica es el excepcional, ya que la prioridad de su autoridad monelaria fue proveer suficiente apoyo al gasto público. Es interesante también el hecho que de los cinco países, solamente EI Salvador tomó medidas explícitas dirigidas exclusivamente a imprimir una cierla eslabilidad al sistema financiero y que en cierla medida alcanzaron resullados fructíferos.

Como se puede apreciar, a pesar de las dificultades que imponen los aspeclos institucionales y estructurales al proceso monetario en paises como los centroamericanos, la dirección de los asuntos monetarios de la región durante los afios 1960-1977 merece un alto calilicalivo. Sin embargo, cabe subrayar que en la mayoría de los casos, el manejo de la política monetaria es mucho más rácil en períodos de expansión que en periodos de recesión.

Asi, en el periodo de 1960-1977, las economlas centroamericanas gozaron de un auge contínuo y creciente, alentado principalmente por los beneficios derivados del esquema del mercado común. Por medio de dicho marco, se logró disminuir considerablemente la presión económica regional, producto de las barreras al comercio, y asi el área cenlroamericana alcanzó un peldaño superior en el proceso de ensanchar su mercado. 
Por último, se debe sefialar que, pese a los obstáculos inslitucionales $y$ estructurales que se han apuntado, no es necesario abarcar todas las medidas y polílicas específicas que ha adoplado un pais para poder llevar a cabo un análisis que presenle un panorama completo del desenvolvimiento económico. En otras palabras, al seleccionar los aspectos monelarios como inslurmento de análisis, se está analizando en forma indirecta pero completa, los aspectos tiscales y cambiarios. Sin embargo, no se pueden cubrir los aspeclos arancelarios, subsidios, etc. Aun asi, dichos aspectos son rellejados y se pueden deducir del panorama monetario, una vez se analice un conjunto de series de liempo.

\section{Dirección y caracteristicas de la politica económica}

Ahora que Centroamérica padece una de las peores disyuntivas económicas de su historia, es pertinente examinar las medidas que se han tomado para aminorar los efectos adversos de la crisis que se vive. Con miras a oblener una mejor visión del panorama monetario que prevalece en la región, a conlinuación se presenlan, por pais, las acciones más importantes que se han efectuado recientemente.

\subsection{Guatemala}

En 1987 la economía gualemalteca registró un crecimiento real del $2.5 \%$ en el Producto Interno Bruto (PIB). Considerando que dicho indicador había registrado un pleno estancamiento en 1986 con una cilra del $0 . \%$, se puede aseverar que Guatemala ha logrado encauzar su economía hacia una trayecloria saludable. Por su parte, la inflación, que habia alcanzado la cifra record del $40.0 \%$ en 1986 , fue reducida al $12.0 \%$. Asi la política deflacionaria aplicada para afrontar la crisis, tuvo el efecto de abalir en forma salisfacloria algunas presiones económicas que se habian gestado durante los últimos años.

En base a estas dos cifras, se puede argumentar, con las reservas del caso, que 1987 constituyó un ano menos pesimista de lo que se creía al principio del mismo. Por lo tanlo, el "Plan de Reaclivación Económica" puesto en vigencia por el Gobierno, se vió coronado por un indisculible éxito relativo. En particular, el Plan logró suavisar las expeclativas de los agentes económicos, ya que, por ejempio, la inversión privada aumentó un $115.0 \%$ y la fuga de capital fue revertida, al ingresar unos US $\$ 200.0$ millones de capitales lugados. Asimismo, las autoridades económicas desplegaron sendos esfuerzos con el objeto de esclarecer las reglas del juego en relación con el sector privado.

A pesar de lo anterior, el éxito logrado no pudo ser complelo pues el desbalance del sector exlerno se ensanchó y el Gobierno entrentó serias dificultades para linanciar sus gastos. El desequilibrio en eslas dos cuentas apunta hacia serios problemas que están aún por resolverse. 
Sin embargo, la diversidad de reacciones ante los desequilibrios internos y externos que enfrentó Guatemala cubrió una amplia gama de comportamientos. Dentro de ellos, sobresalen las medidas para proceder a una mayor integración de los presupueslos monelarios y fiscales, con objeto de cuantificar el verdadero costo fiscal y financiero oculto en la constelación de precios relalivos exislenles, la cual ha sido distorsionada, entre olras, por la falta de congruencia entre la estruclura de subsidios y la estruclura impositiva.

Por su parte, las autoridades del Banco de Guatemala (Banco Central) han reiterado que el desequilibrio en las cuenlas exlernas es el resultado directo del vertiginoso e inesperado aumento del PIB, ya que éste ejerció un efecto-locomotora sobre las importaciones, las cuales se incrementaron en casi un $30.0 \%$ frente a un leve $6.0 \%$ en el valor de las exportaciones; empero, estas últimas acusaron una ampliación mayor en términos quantum. Asi, la cuenta corrienle arrojó un déficit de aproximadamente US $\$ 365.0$ millones, el cual no pudo ser completamente linanciado, ya que el país perdió US $\$ 80.0$ millones de sus reservas internacionales netas. Debe seffalarse que las politicas correctivas, particularmente las cambiarias, fueron un tanto insuticientes para neutralizar los electos adversos que desembocaron en la pérdida de reservas.

Por otro lado, durante los últimos siete anos, el sector fiscal ha mostrado un mejoramiento que debe ser calificado como significativo. Por ejemplo, en el período 1980-84, la relación délicit fiscal/PIB se situó en un $7.0 \%$. En 1987 el valor del indicador acusó un $1.1 \%$, cifra levemente menor que en 1986. A pesar de este indiscutible avance, la economla no absorbió en su totalidad una emisión de bonos del tesoro que pagan una tasa de interés del $14.0 \%$, Ires puntos más que la tasa más alla pagada por el sistema bancario. Este singular hecho implica que el Gobierno tiene que estorzarse aun más para eslablecer la confianza del público y para asegurar un flujo de ingresos coherente con sus gastos.

La preocupación por lo anterior, susciló que el Gobierno impusiera una reforma tributaria casi completa. Dicha reforma, aprobada a finales del año, surgió a pesar de un difícil proceso de consulta y negociación entre los diferentes seclores de la economia. El gobierno espera que los ingresos públicos aumenten Q290.0 millones en 1988 en base a esla reforma.

Parte de las dificultades fiscales se pueden atribuir a un decreto emitido en 1986, el cual obliga al Gobierno Central a repartir a los Gobiernos municipales el $8.0 \%$ de los ingresos públicos. Para 1987, dicha citra podria equivaler a $Q 150.0$ millones. Además otro factor explicativo del desbalance fiscal es que en 1987, el gasto público aumentó más que el ingreso público. 
El panorama presentado debe ser visto a la luz del "Programa de Reordenamiento Económico y Social", puesto en vigencia en junio de 1986. Este Programa perseguia dos objetivos fundamentales:

- Aminorar la creciente ola inflacionaria; y

- Estabilizar la depreciación de la moneda

En base a eslos dos objetivos, quedó claro que la política económica era de corte recesivo. En esa oportunidad, el Gobierno aclaró que el Programa abarcaba dos elapas: una de ajusle y eslabilización y otra de reactivación. Sin olvidar que la inflación se ha contenido, el tipo de cambio se ha eslabilizado y la economía se ha recuperado, se podria afirmar que los objetivos del Programa han sido alcanzados.

Por su parte, el Programa contenía un conjunto de disposiciones de Indole monetaria, crediticia y cambiaria. En términos generales, éstas apuntaban a una reducción de la liquidez bancaria, la eslabilización del lipo de cambio y los precios, así como el apropiado financiamiento a la actlvidad productiva del país. En términos específicos, para coadyuvar al logro de los objetivos del Programa, las autoridades monetarias adoptaron una polltica más acliva en materia de operaciones de mercado abierto y retiro global de los depósilos del Instiluto Guatemalteco de Seguridad Social.

Además, para reforzar la polílica de estabilización, las autoridades aumentaron el encaje legal de un $35.0 \%$ al $\mathbf{4 1 . 0 \%}$ sobre los depositos monetarios y los certilicados de depósito a plazo menores de 30 dias y del $10.0 \%$ al $13.0 \%$ para los depósitos de ahorro y los certíicados de depósitos a plazo mayores de un mes. Asimismo, con el proposito de afianzar la política económica y fomentar el ahorro financiero, las autoridades elevaron la tasa de interés pasiva a un nivel máximo del $11.0 \%$. Para las sociedades financieras las tasas de interés quedaron sujetas a las fuerzas del mercado.

Dentro de los resullados de las medidas de mercado abiento se destaca el hecho que el crédilo nelo al sector público se redujo en un $38.0 \%$ en 1986 y en un $21.0 \%$ en 1987 . Este decremento es indicalivo del carácter restrictivo de la politica monetaria.

Sin embargo, el crédito al sector privado aumentó $9.6 \%$ en 1986 y. sorpresivamente, se disparó $26.0 \%$ en 1987 . Estos aumentos ocurrieron a pesar de las fuertes medidas restrictivas en vigencia. De hecho, estos resultados dejaron a las autoridades un lanlo asombradas. Sin embargo, el Banco Central sostiene que ello fue el resultado de las acciones anticipatorias de los agenles económicos ante la inminente reforma tributaria.

En resumen, la política monetaria en 1986 fue estrictamente dirigida a la estabilización mientras que en 1987 se trató de conjugar el aspecto de 
estabilización con el de reactivación. En particular, la reactivacion se baso en la política cambiaria y en el gasto público. Así, en 1987 el Banco de Guatemala sufrió pérdidas cambiarias por cerca de Q200.0 millones, Además, el Gobierno Central otorgó un aumento en los salarios nominales, inlcusive de una bonificación de $\mathbf{Q 1 0 0}$ por funcionario público. Esla última medida fue apoyada por el sector privado, ya que las cotizaciones al Seguro Social aumentaron en forma casi proporcional, lo que indica un aumento en el nivel de empleo y/o nivel de sueldos.

En lo que respecta al ano 1988, las autoridades monetarias esperan que se mantenga el ritmo de 1987. A ese electo, la Junla Monetaria aprobó una resolución (JM-243-87), en la cual se manlienen en vigencia para 1988 casi todas las normas monetarias que prevalecieron on 1987. Empero, la resolución eslablece una meta crediticia al sector privado que es sumamente restrictiva. De hecho, el saldo de dicho crédito al $\mathbf{3 1}$ de marzo de 1988, no deberá exceder en $1.24 \%$ del saldo de diciembre/87. Por su parte, la resolución también establece un cupo de Q5.4 millones durante los primeros tres meses de 1988 para el redescuento del Banco de Guatemala a los bancos y entidades tinancieras del sistema. El cupo para el primer trimestre de 1987 fue de Q8.75 millones, por lo que se puede deducir el carácter recesivo de esta medida. Es importante sefialar lambién que estas medidas están encaminadas a aminorar las presiones liscales ya que en 1988 vence una serie de emisiones de bonos denominados en divisas y es posible que el Ministerio de Finanzas encuentre serias dificultades para cumplir con dicha obligación.

En to relacionado a las medidas cambiarias, el 21 de agosto de 1987 se estableció la tasa oficial única de 02.5 por US\$1.0 para todas la operaciones del Gobierno con el exterior, quedando siempre en vigencia el mecanismo de tasas libres para las operaciones de compra-venta realizados a través de los bancos. Cabe apuntar que el diferencial entre la lasa libre y la lasa oficial disminuyó persistentemente durante los últimos dos anos y aclualmente se sitúa alrededor del $6.0 \%$. De esta forma, se puede aseverar que el seclor externo no se encuentra acosado. Sin embargo, si se mantiene la presión sobre las importaciones, producto del resurgimiento de la actividad económica, se podrá esperar un leve deterioro del diferencial. Se recalca que el deterioro serla débil pues el conjumo de medidas monelarias y crediticias en vigencia, ejercerian un efecto en el sentido opuesto.

En lérminos generales, el programa monelario de Guatemala es satisfactoriamente coherenle en su conjunto y en forma no ambigua apunta hacia un fuerte control de parte de las autoridades monetarias. Lo anterior se puntualiza, entre otros, en el hecho que las acciones tomadas para controlar la masa monelaria son congruentes entre las fuentes y los usos de la base monetaria. 
Por úllimo, a manera de apreciación se podria sef̂alar que en base a las cirras que arroja el resurgimiento de la actividad económica, las medidas monelarias son sumamente reslriclivas y éslas podrian conducir a que se aborte la recuperación. Por lo lanto, sería razonable esperar un "aflojamiento" en el control monetario dentro de los próximos nueve meses. Lo anlerior no implica necesariamente que el "Programa Económico" será abandonado. Más bien, la coincidencia de ciertos elementos, tales como la redención de bonos emilidos en moneda extranjera y el servicio de la deuda externa, ejercerán fuertes presiones, que en última instancia reducirán el radio de acción de la política económica.

\begin{tabular}{|c|c|c|}
\hline \multicolumn{3}{|c|}{$\begin{array}{c}\text { Cuadro No. } 1 \\
\text { Guatemala: Indicadores selecclonados }\end{array}$} \\
\hline & 1986 & 1987 \\
\hline PIB (\%) & 0.0 & 2.5 \\
\hline Inflación (\%) & 40.0 & 12.0 \\
\hline Exporlaciones (\%) & 2.0 & 6.0 \\
\hline Importaciones (\%) & -14.0 & 30.0 \\
\hline (Délicil) Cuenta Corriente (Millones) & US\$ 17.6 & US $\$ 356.0$ \\
\hline Variación Reservas Netas (Millones) & US\$ 101.8 & -US $\$ 80.0$ \\
\hline Relación Déficit/Fiscal/PIB (\%) & 1.6 & 1.1 \\
\hline Encaje Legal (\%) & 35.0 & 41.0 \\
\hline Tasa Interés Máxima (\%) & $\ldots$ & 11.0 \\
\hline Crédito Neto Público (\%) & 38.0 & -21.0 \\
\hline Crédilo Neto Privado (\%) & 9.6 & 26.0 \\
\hline Pérdida Cambiaria (Millones) & --- & Q 200.0 \\
\hline Tipo de Cambio Oticial & Q 1.0xUS $\$ 1.0$ & O $2.5 \times$ US $\$ 1.0$ \\
\hline
\end{tabular}

Fuente. Banco de Guatemala

\subsection{El Salvador}

La politica monetaria de El Salvador no ha podido eludir ni conlrarrestar los efectos desfavorables que se derivan de la inestabilidad politica que viene agobiando al país desde 1979. Aun cuando se logró revertir la tendencia de la actividad económica, de $-0.1 \%$ en 1986 a $+06 \%$ en 1987 , la política monetaria ha perdido su poderosa capacidad estabilizadora para convertirse en un instrumento económico acomodalicio, al igual que muchos más. 
Cabe indicar que la función más importanle de la política monetaria se ha desvanecido no por el mal manejo, sino por razones mayores que incluyen la dimensión socio-política, la falla de disciplina en el sistema financiero y en los sectores relormados. La situación ha sido complicada aun más por el laxo manejo de los aspectos fiscales y por los inquietantes desequilibrios en las cuentas externas. Con todo ello, el año 1987 arrojó ciertas cifras que parecieran indicar un cierto contenimiento del persistente deterioro.

El ritmo inflacionario, que parecia imparable en 1986 con una tasa del $32.0 \%$. fue reducido a $20.0 \%$ en 1987 . El mejoramiento tue un resultado alentador de 10 que pareciera una profundización en la instrumentación de las herramientas de control monetario. Asi, por ejemplo, al finalizar el año 1987, todos los bancos se encontraban cumpliendo las metas de encaje legal, lo que no sucedió en 1986. Asimismo, los medios de pago crecieron solamenle en $7.5 \%$ en contraste con 1986, cuyo incremento fue de $29 . \%$. Sin embargo, no se puede descartar la posibilidad que el desbalance monelario de 1986 tue producto parcial de la modificación cambiaria, la cual sufrió una devaluación nominal del 100.0\% en enero de ese afio Como se sabe, el tipo de cambio aumentó de C2.5 a C5.0 por US\$1 0 .

A pesar de la devaluación cambiaria, el déficit de la balanza comercial aumentó de US $\$ 180.0$ millones en 1986 a US $\$ 402.0$ millones en 1987 $(120.0 \%)$. Las exportaciones decrecieron $24.0 \%$, mienlras que las importaciones se ampliaron en $4.0 \%$. El deterioro es parcialmente atribuible al entomo internacional adverso, en particular por la drástica reducción de los precios del café y el alza en los precios de pelróleo.

No obstante que las transierencias unilalerales privadas repuntaron en un $22.0 \%$ y los pagos por servicios netos se redujeron en $85.0 \%$ la cuenta corriente arrojó un déficit de US $\$ 186.0$ millones en 1987, el cual es sustancialmente mayor al de 1986 que fue de US $\$ 74.0$ millones. Sin duda alguna, el comporlamiento de la cuenta corriente refleia un fuerte debilitamienlo de la capacidad exportadora del país, cuyo saneamiento va más allá de las medidas de indole cambiario.

Por su parte, el comportamiento global de la balanza de pagos no deja de ser un elemento de perturbación. Por ejemplo, las reservas internacionales netas aumentaron US $\$ 75.0$ millones en 1986; empero, por resolución de la Junta Monelaria, se revalorizó la proporción correspondiente al oro en las reservas brutas, lo que significó un aumento contable de US $\$ 90.7$ millones. A su vez, las reservas internacionales netas se incrementaron en US $\$ 50.7$ millones en 1987 , apoyadas por un alza en las transferencias unilaterales privadas (US $\$ 40.0$ millones) y las oficiales (US $\$ 115.0$ ). 
Es igualmente preocupante el hecho que las necesidades para el servicio de la deuda externa han aumentado desmesuradamente y no se ve en el horizonte ningún tipo de programa de renegociación de la misma de parte del gobierno. Asi, no sería sorpendenle una nueva modificación cambiaria en el Iranscurso del ano o a principios de 1989.

Es de subrayarse, también los indicios que se desprenden de las cuentas del sector público. La brecha en dichas cuentas se amplió de US\$55.6 millones en 1986 a US $\$ 71.0$ millones en 1987. Empero, más ominosa es la estructura de financiamiento del mismo. En 1986, el financiamiento del déficit fue del $100.0 \%$ via fuentes externas, mientras que en 1987 el tinanciamiento exlerno solamente cubrió el $42.0 \%$. Lo anterior implica una fuerte monetización, ya que tendria que ser financiado por el Banco Central y el sistema financiero. Estimaciones para 1988 indican que el déficit puede aumentar $100.0 \%$ y se contempla financiar un $50.0 \%$ vía fuentes internas.

En base al desenvolvimiento económico y financiero presentado, se puede aseverar que la política económica del país se inscribió en un marco de fatiga interna $\theta$ inestabilidad, afectada por una enraizada incertidumbre. Aun cuando se logró un moderado crecimiento económico y también atemperar la inflación en 1987, es dudoso que los alcances en el liempo de estos logros marquen un punto de inflexión en el devenir del pais. A esta reflexión la apoya el vaivén que ha reflejado la política monetaria en los últimos dos anos.

En enero de 1986, las autoridades monetarias anunciaron que se hacia efectiva la devaluación de la moneda en un $100.0 \%$. Conjunlamente, se anunciaron acciones adicionales, orientadas a apoyar la primera. La tasa de redescuento fue elevada dos puntos, al igual que las lasas pasivas del sistema financiero. Asimismo, se incrementó del $25.0 \%$ al $40.0 \%$ a las companias de seguros el porcentaje de inversiones obligatorias en títulos valores emitidos o garanlizados por el Estado. Por su parte, el encaje legal se mantuvo al $20.0 \%$, con el pre-aviso que éste subiria a $25.0 \%$ en abril, pero seria nuevamente reducido a $20.0 \%$ en agosto; lambién, se le autorizó al Banco Hipolecario emilir valores por . US\$12.4 millones al $13.0 \%$ anual, cuyo nivel compite con las lasas del sistema financiero.

En términos generales el conjunlo de medidas apuntaba directamente a reducir el desequilibrio del sector externo, vía la modificación cambiaria y el retraimiento en la liquidez inlerna. Como se debe sefalar, la necesidad de contrarrestar factores críticos externos, asi como el imperativo de introducir procesos de corrección para estabilizar el mercado montario, tendió a reflejarse en la variación cambiaria como instrumento básico del ajuste. 
debe sef́alar, la necesidad de contrarrestar factores críticos externos, así como el imperativo de introducir procesos de correción para estabilizar el mercado monetario, tendió a rélejarse en la variación cambiaria como instrumento básico del ajuste.

Bajo un enfoque tradicional, el programa se podria considerar perfectamente normal y convencional. Empero, a lo largo de 1986, los sucesos financieros parecian indicar que se habia perdido el control del programa.

Como se sefialó anteriormente, en 1986 los medios de pago se aceleraron a una tasa del $29.0 \%$, producto parcial del aumento vertiginoso del multiplicador monelario. Como se sabe, la autoridad monetaria no puede ejercer control direclo sobre el multiplicador; este último depende, al corto plazo, exclusivamente del comportamiento del público no bancario y del sistema financiero no consolidado. Así, la incertidumbre que arroja la situación socio-política del pais, puede explicar las acciones del público no bancario. Por su parte, partiendo del hecho que los bancos no cumplieron con el encaje legal en 1986, se puede concluir que la falta de control monetario obedeció a la escasez de disciplina por parte del sistema bancario.

En ese orden de ideas, la auloridad monetaria no consideró oportuno apegarse al programa adoplado a comienzos de año. Como se habia preanunciado, el encaje legal bajó al $20.0 \%$ en agosto (1986). Además, en septiembre se redujo de nuevo al $35.0 \%$ las inversiones obligatorias de las companías de seguros en tílulos públicos; la misma tasa se redujo al $25.0 \%$ en noviembre. Como si eso fuera poco, en noviembre lambién se redujo el encaje legal, para ciertos depósitos, al $15.0 \%$. Por su parte, en marzo de 1987, la Junta Monetaria autorizó una reducción de dos puntos a las tasas pasivas $y$ activas del sistema financiero.

Con esta úllima medida quedó claro que la autoridad monetaria había abandonado el programa de eslabilización pueslo en práctica al principio de 1986. En esa oportunidad, las autoridades alegaron que el programa no habia sido acogido con beneplácito por los sectores populares. Además, la sequia y el movimienlo telúrico de octubre, habian desvirtuado por completo el esfuerzo de estabilización.

De hecho, la disminución en las tasas de interés sehalaba una reversión en la dirección de la política monetaria. Así, dicha decisión se justificó bajo el argumento que ésle tenía como objetivo "estimular actividades productivas y atender necesidades de vivienda en estralos de bajos ingresos". En otras palabras, la reactivación económica habia suslituido a la estabilización económica como objetivo de la política monetaria.

Aforlunadamnte. cuando se dispuso como meta económica la reaclivación, la autoridad monetaria ya se había percatado del tenue vínculo 
efectivo entre el inslituto emisor y el sistema bancario. A ese efecto, conjuntamente con las medidas de reactivación, se impusieron normas mucho más rígidas en cuanto al ordenamiento del sistema financiero, el cual correclamente había sido diagnoslicado como el flanco más débil de la polílica monetaria y crediticia.

Dentro de las medidas implantadas se encuentra un plan de estabilización para cada banco, el cual incluye un fuerte seguimiento para que cada uno de ellos cumpla con las melas impuestas; entre las metas más importantes se encuenlra el estricto cumplimiento al encaje legal y a los lopes de cartera, inclusive de su estruclura por actividad económica. Asimismo, tomando plena conciencia que el mejor y único mecanismo de Iransmisión de la política monelaria del pais es el sistema financiero, se establecieron metas de rentabilidad del $15.0 \%$ para cada banco.

Sin embargo, solamente cuatro de ellos cumplieron con dicha meta. Al indagar el por qué los cinco bancos reslantes no habian cumplido las metas de rentabilidad, se logró establecer que éstos estaban vinculados via el crédito, a empresas ligadas a la retorma agraria. Asi, se pudo identificar que la falta de eficacia de la polílica monetaria obedecia parcialmente a razones técnicas y no a la política propiamente dicha.

Para solventar el problema que ocasiona lo anterior, se está considerando hacer una consolidación del sistema bancario, el cual reduciría el número de bancos de nueve a seis y las asociaciones de ahorro y préstamo de siete a cinco. Sin embargo, más de un observador ha argumentado que el problema de la banca es que las autoridades mismas no se han definido en cuanlo a su función: Son los bancos agentes de creación de renlabilidad o son canalizadores de credito. Realmente, estas dos alternativas son muy pocas y exlremas. dada la realidad nacional.

A pesar de las medidas que se han tomado para fortalecer el flanco débil que representa el sistema tinanciero, el desequilibrio monetario todavía persisle. Esto se evidencia en diferentes dimensiones.

No obstante el esfuerzo por imprimir eslabilidad y control a la oferta monetaria (los medios de pago aumentaron solamente $7.5 \%$ en 1987), el lado de la demanda manifiesta una inquietante inestabilidad, que ha derivado en un poco controlable proceso de "dolarización". Por otro lado, lanto la brecha entre la eslructura de la cartera por plazos y la esiructura de la captación de recursos por plazos, como también el porcentaje del crédilo orientado a refinanciamiento sefialan que los desbalances financieros y monetarios están siendo propulsados por fuertes presiones, que se originan en los ámbitos económico y polílico.

En conclusión, se puede afirmar que el comportamiento de la política monetaria en 1987 luvo un éxito relalivo en comparación a 1986. A pesar de ello, ciertos indicadores, tales como el comportamiento del tipo de 
cambio real y la tasa de interes real, sefialan que todavía existen graves distorsiones de los precios relativos, que el costo social del proceso politico que se vive es sumamente alto, y que el papel eficiente que se debe de esperar del sistema linanciero está aún por realizarse. Aún más, una mayor congruencia entre los sectores reales y monetarios, con el objeto de imprimir estabilidad en las expectativas de los agentes económicos, deberá esperar para que la dirección del ajuste sea oportuna en cuanlo a los parámetros polílicos, dentro del cual se circunscribe.

\begin{tabular}{|c|c|c|c|c|}
\hline \multicolumn{5}{|c|}{$\begin{array}{c}\text { Cuadro No. } 2 \\
\text { El Salvador: Indicadores selecclonados }\end{array}$} \\
\hline & \multicolumn{3}{|c|}{1986} & 1987 \\
\hline PIB (\%) & & -0.1 & & 0.6 \\
\hline Inflación (\%) & & 32.0 & & 20.0 \\
\hline Medios de pago (\%) & & 29.0 & & 7.5 \\
\hline Balance Comercial (Millones) & - US\$ & 180.0 & US $\$$ & 402.0 \\
\hline Exportaciones FOB (Millones) & US\$ & 755.0 & US\$ & 573.0 \\
\hline Importaciones CIF (Millones) & US $\$$ & 935.0 & US\$ & 975.0 \\
\hline Transferencias Privada Netas (Millones) & US $\$$ & 183.0 & US\$ & 223.0 \\
\hline Servicios Netos (Millones) & - US\$ & $74.1-$ & US\$ & 5.7 \\
\hline Cuenta Corriente (Millones) & - US\$ & $71.4-$ & US\$ & 186.0 \\
\hline Variación Reservas Netas (Millones) & US\$ & 75.0 & US $\$$ & 51.0 \\
\hline Revalorización Oro (Millones) & US\$ & 91.0 & & $\ldots$ \\
\hline Délicil Fiscal (Millones) & US\$ & 56.0 & US $\$$ & 71.0 \\
\hline
\end{tabular}

Fuente: Banco Central de Reserva de El Salvador

\subsection{Honduras}

La recuperación económica de Honduras continuó afianzándose en 1987, al aumentar la tasa de crecimiento del PIB a $4.2 \%$, lo cual se reflejó en variaciones significativas en los sectores agricolas, industrial y construcción. Mientras tanto, la presión inflacionaria continuó cediendo al situarse al $2.5 \%$ la tasa más baja en la región centro y sudamericana. Sin embargo, esa cifra podrla ser levemente mayor si se considera la sobrevaluación del lempira, la cual absorbe la inflación generada internamente.

Bajo estos alentadores indicios, repercutió nocivamente sin duda el factor empleo, que tiende a distorsionar las cifras oblenidas. Considerando que la tasa de desempleo se ha colocado alrededor de un recal- 
citrante $30.0 \%$ se podria argumentar que la economia se enfrenta ahora con un debilitamiento de las fuentes internas de crecimiento, teniendo que apoyarse aun más en las fuentes externas. Debido a la connotación social del desempleo, este lenómeno constiluye una de las características más preocupantes del panorama de la reactivación económica. Asi las vinculaciones esperadas entre la producción y el empleo no se han verificado complelamenle en la experiencia reciente.

No obstante la persistencia del problema del desempleo, es importante destacar que el comportamiento del crecimiento y de la ińlación tienden a demostrar que los instrumentos de la politica económcia han jugado un papel importante en los resullados logrados. En particular, los objelivos de la política monetaria en 1987 fueron identilicados bajo los siguienles términos: Recuperación económica con eslabilización; y, en ese sentido, se redujo la lasa máxima de interés en dos puntos y se disminuyó la lasa de redescuento a la producción agricola y ganadadera.

En contraste, el programa monetario para 1988 está orientado a reducir las presiones inflacionarias, consolidar el tipo de cambio oficial, moderar el crecimiento de la base monetaria y controlar el electo inflacionario de la conversión de la deuda externa. Además de los esfuerzos direclos de parte del Banco Central, el programa se apoyará en medidas fiscales y de comercio exterior.

En el campo fiscal, el programa de 1988 contempla incrementar el ahorro del sector público y de esa forma reducir el abullado déficit fiscal. De hecho, esle último se ha situado a un $7.1 \%$ en relación al PIB, durante los dos últimos años. Se debe sefialar que para que dicho indicador guarde congruencia con el sistema financiero, este no debería sobrepasar el $3.0 \%$.Consecuentemente, no se puede descartar la afirmación que el problema fiscal ha sido considerable y dilíicil de superar.

Es lambién muestra de preocupación la fuente de financiamiento del déficit. Por ejemplo, la relación financiamiento interno/déficit lue de $24.0 \%$ en 1984 , mientras que para $\{987$ la relación se incrementó a $54.0 \%$. Aunque se podría argumentar que esta tendencia tiende a desacelerar el crecimienlo de la deuda externa, no se puede hacer caso omiso de la presión que causa el tinanciamiento interno al sistema financiero nacional.

De hecho, el proceso de formación de capilal se encuentra minado por los obstáculos que enirenta el proceso de conversión de capilal financiero a capital productivo. Uno de estos obstáculos radica en el linanciamiento interno del déficit público. Asi, los bonos eslatales están rindiendo el $20.0 \%$, libre de impueslos." Ante esta rentabilidad, una buena

\footnotetext{
- Inlorpress Centroamericana, 14 de enero de 1988, Pág. No.9
} 
proporción de los fondos financieros privados disponibles son absorbidos por las necesidades del sector público, desplazando la actividad inversionista producliva del seclor privado.

El efecto de desplazamiento también se origina por medio de la estruclura y los niveles de lasas de inlerés que prevalezcan en un momento dado. Asi, por ejemplo, el nivel de la lasa de interés real en Honduras, es la más elevada en la región, no obslante la reducción de dos puntos en 1987. Dicho nivel desincetiva la inversión productiva y ahoga al sistema financiero al obligarlo a mantener allos niveles de liquidez.

A la luz de los niveles de las tasas de inlerés, se pone en entredicho que tan saludable ha sido la recuperación económica del país. Como se seffaló, la tasa de crecimiento real fue de $4.2 \%$. Asi, es dable afirmar que dicha recuperación se suslenló en el gaslo corriente de los sectores público y privado y en el flujo de donaciones. Lo anterior se deriva del hecho que el nivel de exportaciones se manluvo al mismo nivel que en 1986; por su parte, las altas tasas de interés real indican que la dinamización de la inversión privada no pudo ser tan acentuada como se puede haber creído. Aun más, el monlo de donaciones oficiales fue levemente menor en 1987 que en el año anterior. Consecuentemente, la estructura del PIB, por el lado del gasio, no es sostenible al mediano plazo y es posible que la efectividad de los instrumentos de polílica económica haya alcanzado su punto crilico, por lo que no se puede descarlar un viraje en la dirección de los mismos en los próximos meses.

El comportamiento de la balanza de pagos en 1987 lambién arroja indicios de presiones subyacentes. Aun cuando la balanza comercial se mantuvo relativamente estática, las exportaciones cayeron $3.2 \%$ y las importaciones crecieron $2.2 \%$, el enorme peso del servicio de la deuda externa, un poco más de US $\$ 100.0$ millones, determinó un sensible deterioro del déficit de la cuenla corrienle, el cual aumentó de -US\$105.0 millones en 1986 a -US\$183.0 en 1987.

Por su parte, las reservas inlenacionales netas mostraron un relativo mejoramiento en cuanto aumentaron en US $\$ 42.0$ millones. Sin embargo, cabe sefialar que dicho aumento probablemente obedeció a un aumento en el nivel de endeudamiento exlerno, ya que las transterencias unilalerales oficiales mantuvieron casi el mismo nivel de 1986 y el flujo de inversiones direclas y de cartera no mostró ningún repunle significativo. Pese a la mejoria de las reservas internacionales netas, el saldo de la misma se ha siluado en niveles negativos desde 1982, por lo que se puede concluir que el panorama del sector externo es precario y lejos de una solución inmediala.

En lo que respecta a la dirección de la política económica, existen inequivocos indicios de que en 1987 se dió un viraje respecto a 1986. 
Por un lado, el crédito interno del sislema financiero consolidado se incremenló en 1987 en un $15.3 \%$, lo que contrasta con el moderado aumento de $7.7 \%$ en 1986 . Cabe sefialar que el incremento, en términos porcentuales, al sector privado fue similar a del sector público, $15.1 \%$ vs. $15.8 \%$.

Como se sabe, en economias pequefias y abierlas, como las centroamericanas, el instrumento monetario más eficaz está constituido por la disponibilidad del crédito. En tal senlido, se puede generalizar que la política económica de Honduras en 1987 se caracterizó por su marcada orientación hacia la reactivación económica. Existen varios rasgos que apoyan esta aseveración.

En primer lugar, la emisión monetaria del Banco Central acusó un aumento del $13.4 \%$ en 1987, frente a un $4.8 \%$ en 1986 . Asimismo, el crédito inlerno del instiluto emisor se aceleró a un rilmo del $9.9 \%$ en 1987 , en contraste con un leve $4.1 \%$ en 1986 . En segundo lugar, los dos factores anteriores se traducen en un cambio en la misma dirección de los medios de pago. Asl, dicho rubro se elevó 18.3\% en 1987, mientras que en 1986 solamente acusó un incremento del $9.7 \%$.

Cabe sefhalar que los esfuezos para lograr la reactivación económica se apoyaron en un cambio drástico en la estructura del crédito interno otorgado por el Banco Central. De esa lorma, la variación del crédito neto al secior público fue negativa en 1986 , reduciéndose en $11.0 \%$, mientras que para el sector privado se aumentó en $18.0 \%$, superando en $5.0 \%$ la mela eslablecida. En cambio, para 1987 el crédito neto al sector público se elevó en $20.0 \%$, frente a un $2.7 \%$ para el sector privado (bancario). Del cambio en la estructura del crédilo interno se puede colegir que en 1987, el programa monetario colocó al sector público como propulsor de la economia. Sin embargo, como se señaló anteriormente, este factor interno de crecimiento se encuentra al borde del agotamiento por su reducida capacidad de endeudamiento.

No es un secreto, por otra parte, que la reactivación económica solamente se apoyó en el desmesurado aumento (16.0\%) de la base monetaria. El dinero secundario también jugó un papel importante. De hecho, el multiplicador monetario aumentó diez puntos, colocándose a un nivel histórico (reciente) relativamente alto. Dicho incremento obedeció fundamentalmente a la reducción de dos puntos en las lasas de interés, el cual de por si es un aliciente más para la reactivación.

Por úllimo, para 1988 se podría esperar un nuevo viraje en la dirección de la polítlca económica. La reactivación de la economía en 1987 fue mucho más acelerada de lo previsto y, dado el marco en donde se circunscribe la economia, es imposible sustentar el mismo ritmo durante un ano adicional. En ese sentido, es probable que en 1988 se lomen 
medidas restrictivas. De hecho, el programa para 1988 contempla "aumentar el ahorro público y moderar el crecimienlo de la base monetaria."

En resumen, es indisculible que el programa económico de 1987 logró un rotundo éxito y es razonable considerarlo como uno de los más sólidos de la región. Empero, todavía existen algunos flancos débiles que deberán ser enitrenlados. Entre ellos sobresalen la sobrevaluación de la moneda, el proteccionismo comercial, el desempleo y el nivel de ayuda externa. Es indiscutible, también, que estos cuatro elementos están entrelazados entre sl.

\begin{tabular}{|lrr|}
\hline \multicolumn{3}{|c|}{$\begin{array}{c}\text { Cuadro No. 3 } \\
\text { Honduras: Indlcadores Selecclonados }\end{array}$} \\
\hline & 1986 & 1987 \\
\hline PIB (\%) & 3.0 & 4.2 \\
Inflación (\%) & 4.4 & 2.5 \\
Desempleo (\%) &.- & 30.0 \\
Variación Tasa de Interés &..- & -2.0 \\
Délicil FiscalPIB (\%) & 7.1 & 7.1 \\
Financiamiento Intemo/Déficit Fiscal (\%) & 43.0 & 54.0 \\
Importaciones (\%) & 0.6 & 2.2 \\
Exportaciones (\%) & 12.8 & -3.2 \\
Cuenta Corriente (Millones) & 105.0 & US\$ \\
Variación Reservas Netas (millones) & US\$.0 \\
Crédito Interno Sistema Consolidado (\%) & 6.0 & US\$ \\
Emisión Banco Central (\%) & 7.7 & 15.0 \\
Crédito Intemo Banco Central (\%) & 4.8 & 13.4 \\
Medios de Pago (\%) & 4.1 & 9.9 \\
Crédito Neto Sector Público (\%) & 9.7 & 18.3 \\
Crédito Neto Sector Privado (\%) & -11.0 & 20.0 \\
Base Monetaria (\%) & 18.0 & 2.7 \\
\hline
\end{tabular}

Fuente: Banco Central de Honduras

\subsection{Nicaragua}

En 1987 la economia nicaraguense continuó arrojando cifras alarmantes que tienden a demostrar el persislente delerioro del nivel de actividad comercial. Como puede inlerirse, el PIB real acusó un nivel negativo, conjuntamente con una tasa inflacionaria nunca antes registrada 
en tiempos recientes en el área centroamericana. El debilitamiento económico y la poca probabilidad de una reactivación ecónomica, son los rasgos que caracterizan el devenir de la producción en esta nación centroamericana.

Además de la poca capacidad de los instrumentos de política económica para aminorar los problemas subyacentes, se debe senalar que otros factores, lales como el impulso recesivo resultante de un bloqueo comercial de parte de los suplidores y la renovada depresión de los términos de intercambio, se han conjugado para hacer de la política económica tradicional un mero concepto sin ningún arraigo en el quehacer económico. Ante este marco, no resulta tácil analizar la política económica vigente. Sin embargo, la descripción de algunas variables puede permilir que se obtenga una noción de las posibles trayectorias por las cuales pueden atravezar la economia de este país. Denlro de estas variables se destacan: los eslrangulamientos de la olerta de bienes y servicios, la reducción en el ritmo del comercio intrarregional, la progresiva reducción de divisas y la falla de congruencia entre las polílicas de precios e ingresos.

Las variables senaladas repercuten en forma magnificada sobre el sector externo. De hecho, es en este sector en donde más se ha acentuado la vulnerabilidad que circunscribe a toda la aclividad productiva. El saldo en la cuenta corriente se siluó en -US\$680.0 millones en 1985 , el cual se incrementó a -US\$780.0 millones en 1986; las cifras preliminares para 1987, lo han estimado en -US\$720.0 millones. No obstante el alto délicit, las obligaciones por retribuciones a las inversiones alcanzaron casi US $\$ 200.0$ millones en 1987 , de los cuales solamente se cancelaron US $\$ 12.0$ millones.

A raíz de lo anterior, la deuda exlerna ha superado la cifra de US $\$ 6,000.0$ millones, la más alla de Centroamérica. Asimismo, durante el período 1985-1987, el país perdió más de US $\$ 275.0$ millones en reservas internacionales. Estas penosas tendencias han conducido a fuertes presiones, las cuales se han hecho sentir principalmente en los sectores productivos que dependen de importaciones para realizar sus operaciones.

Por su parte, el agolamiento del sector extemo se ha visto acompanado por el desquiciamiento de las finanzas públicas. Ello no es sorprendente, ya que si algo se puede aseverar sobre la politica económica, es que ésta ha sido formulada en función de las actividades de defensa. No obstanle el logro de reducir la relación délicit cuenta corienle/ingresos corrientes de $48.0 \%$ en 1985 a $36.0 \%$ en 1987 , el linanciamiento externo fue menor del $3.0 \%$ para dichos afios. Considerando la magnitud del déficil, to anterior significa una "sobre-monetización" de la economia, con todo to que ello implica, particularmente en el sector financiero. 
En relación a este seclor, la intormación preliminar para 1987 mueslra una preocupante lendencia. Así, por ejemplo, los activos líquidos aumentaron $235.0 \%$ en 1986 y $550.0 \%$ en 1987 , lo que indica un exorbitante exceso de liquidez. Igualmente inquietante, la relación medio circulante/activos líquidos se situó en $80.0 \%$ en 1985, de por si elevada, y aumentó a $94.0 \%$ en 1987 . Esta trayectoria evidencia una peligrosa desintermediación financiera, que a la postre significaria una bancarrota completa del sislema financiero.

A la luz de los números mencionados, es dable opinar que la función de la autoridad monetaria de Nicaragua no es conmensurable con la que se podria esperar de una banca central tradicional. La base monetaria se elevó $600.0 \%$ en 1987 , Irente a un relativamente inocuo incremento de $230.0 \%$ en 1986. (Un aumento del $20.0 \%$ es de por si potencialmente inllacionario). Por su parte, en 1987 , el $81.0 \%$ de la base monetaria lo constituia la emisión, siendo el residuo de $19.0 \%$, que corresponde al encaje legal, insuficiente para apoyar las necesidades de financiamiento del sector públič́o.

Vislo desde olro ángulo, en 1987 el crédito neto del banco central al sector público se siluó en $50.0 \%$ del lotal, habiendo decrecido del $80.0 \%$ en 1985. Sin embargo, el crédito del banco central al Fondo Nicaraguense de Inversiones (entidad pública) fue de 5.0\% del tolal en 1985, frente a un incremenlo al $27.0 \%$ del tolal en 1987.

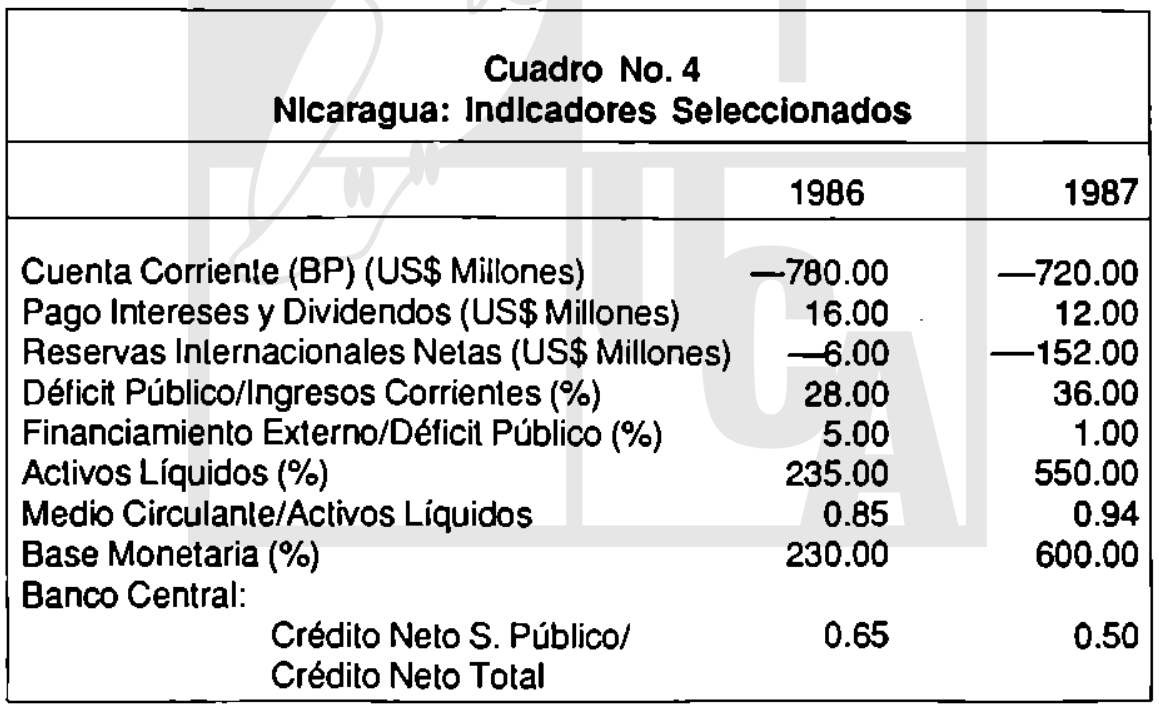

Fuente: Banco Central de Nicaragua 
Como se podrá colegir, las medidas monetarias y crediticias realizadas tienen muy poco que ver con la función reguladora que normalmenle se le asigna a una autoridad monetaria. Empero, frente a la avalancha de sucesos que han recaido sobre Nicaragua, el margen de maniobra de su autoridad monetaria es práclicamente exiguo, aunque existen algunas medidas que lo pueden ensanchar.

Una de ellas, es una reforma monetaria. De hecho, recientemente se efectuó un arreglo monetario de inmensas repercusiones (febrero 1988). Aún cuando los resultados están por determinarse, este instrumento, si se le puede denominar así, es el úllimo del arsenal para restituir la estabilidad financiera.

\subsection{Costa Rica}

La consolidación económica que se venía evidenciando en Costa Rica desde 1983, tuvo un fuerte tropiezo en 1987. Las metas de crecimiento económico y de inflación quedó obvió, fueron establecidas bajo premisas optimistas. Así, en 1986 el PIB registró un asombroso crecimiento del $4.2 \%$, mientras que en 1987 la cifra se redujo a $3.0 \%$. Aun cuando la cifra lograda se sitúa satisfactoriamente por encima del promedio de la región, las proyecciones a principios de ano la hablan estimado entre el $3.5 \%$ y el $4.0 \%$. Por su parte, el ritmo inflacionario se aceleró de $11.8 \%$, en 1986, a $17.0 \%$ en 1987, no obstante que la meta era de $10.0 \%$.

Es notorio el hecho también que a pesar que las autoridades monelarias caracterizaron la política monelaria en 1987 como restrictiva, las importaciones aumentaron US $\$ 200.0$ millones $(18.0 \%)$, tomando por sorpresa tanto a las autoridades como a todos los sectores económicos. Consecuentemente, el déficil en cuenta corriente alcanzó la cifra imprevista de US\$220.0 millones (En 1986, el nivel del déficit fue de US\$70.0 millones, el cual fue un claro éxito de la política económica puesta en práctica). Asl, Costa Rica perdió US\$60.0 millones de sus reservas netas en 1987, bajo el amparo de donaciones oficiales de US\$120.0 millones. Esta precaria situación impidió que se cumpliera a puntualidad el pago de intereses de la deuda externa por cerca de US $\$ 100.0$ millones.

Por olro lado, las cuentas del sector público continúan siendo un elemento de rigidez en el desenvolvimiento de la economia. No obstante la política restrictiva en vigencia, la inflexibilidad en la esiructura del gasto público imprime una marcada extrechez en el radio de acción en donde opera. Tratando de ampliar el margen operativo, el gobierno impulso la colocación de CCR7,000.0 millones en bonos fiscales. Sin embargo, las condiciones en el mercado financiero son tan inseguras, que solamente se coloco el $\mathbf{4 3 . 0 \%}$ de la emisión. 
Ante esle Iracaso y ante la falta de capacidad para reducir la relación déficit /PIB a niveles congruenles con la política económica global, el gobierno procuró solidificar su siluación financiera por medio de una reforma tributaria que toca prácticamente todas las actividades que generan ingresos. Asl, se ha estimado que dicho "paquele" conlribuyó a aumentar la recaudación fiscal en CCR1,000.0 millones en 1987, y se espera recaudar CCR4,000.0 millones en 1988. Cabe sehalar, que al igual que en Gualemala, las retormas tributarias han generado fuertes oposiciones pollticas.

Los obstáculos estructurales que impiden que Costa Rica alcance su pleno polencial en la dimensión económica, como por ejemplo el alto nivel de la relación servicio deuda externa/exporlaciones, han obligado a las autoridades económicas a poner en práctica novedosos esquemas de politica económica. Dentro de estos esquemas resallan a la vista las medidas monelarias y cambiarias.

La política cambiaria cubre varios campos y, básicamente, está orientada a apoyar las medidas de control de liquidez interna. Esto último se trata de lograr por medlo de una serie cronológica de mini-devaluaciones, cuyo objetivo final es el de aminorar las presiones a la tasa de interés, y por ende al mercado monetario. Por otro lado, la polltica cambiaria persigue restltuir, en forma casi automática, la competitividad externa por medio de un ajuste directo al tipo de cambio real. Asimismo, las regulaciones que sustentan a la polltica cambiaria facilitan la concreción de la polltica monetaria y crediticia. Asl, se podrla aseverar que el pivote de la politica económica en general radica casi por completo en la política cambiaria.

Por su parte, la polftica monelaria propiamenle dicha se ha configurado bajo una visión sumamente caulelosa. Durante los úllimos tres anos el crédilo interno nelo público ha sido práclicamente nulo, forzando al gobiemo a emitir bonos en los mercados para su propio financiamiento. No obstanle, estas medidas han presionado aun más a las tasas de interés.

Es pertinente sefialar que aun cuando el crédilo al sector público estuvo constrenido, el crédilo al sector privado creció en un $25.6 \%$ durante el ano 1987, casi el doble de lo programado. El comportamiento de este rubro explica en buena parte el desequilibrio en el seclor externo $y$, también, la devaluación mayor a la esperada.

Asimismo, el deterioro tinanciero experimenlado en $1987 \mathrm{~s} \theta$ manifestó en diversas formas. La herramienta monetaria que se ha utilizado con mayor intensidad, por constituir la más efectiva, es la emisión de bonos de estabilización monetaria. Asl, por ejemplo, aun cuando el saldo de dichos bonos aumentó durante el ano 1987, el incremento obedeció a las 
ventas al sector público no financiero y a los títulos emitidos por la conversión de la deuda externa; en contraste, el sector privado exigió una redención de casi CCR1,500.0 millones, de un total de CCR11,764.0 millones emitidos. Este flujo evidencia una pérdida de confianza de parte del sector privado y, además, anticipa una inminenle expansión monetaria que podría desvirtuar las medidas de control monetario en el futuro cercano.

En el mismo orden de ideas, el sislema bancario privado sulrió un descalabro que arrojó una significativa serie de quiebras. A la fecha, el sistema tinanciero nacional no ha recuperado su compostura. Así, la auloridad económica se vió forzada a inlervenir abiertamente y llevar a cabo una completa revisión de la política y de las normas que regulan este sector bancario.

Por su parte, el gobiemo ha anunciado que se conlinuará con la politica de liberalización del sistema financiero. Sin embargo, cabe sefialar que el conjunlo de quiebras indica que el proceso financiero que se está llevando a cabo ha sido realizado en forma quizá precipilada y sin considerar las implicaciones que se obtendrían de un cuidadoso análisis de costo/beneficio.

Otra dimensión del problema financiero también se pone en evidencia al examinar el comportamiento de la relación entre la base monetaria y el multiplicador monelario. La trayectoria del primero mostró un decremento de casi un $2.5 \%$; ello podría indicar una polílica monetaria relativamente exilosa. Sin embargo, el decremento resultó de los menores montos de depósitos que mantuvieron los bancos comerciales en el Banco Central; otro factor explicativo importante tue la pérdida de reservas internacionales nelas. Por su parte se debe sef́alar que la reducción en el crédito nelo al gobierno obedeció enteramente a un movimiento contable y no a un esluezo fiscal, por lo que no implicó una absorción electiva de fondos por parte del Banco Ceniral.

Considerando que los medios de pago aumenlaron $17.2 \%$ en 1987. cifra igual a 1986, es dable alirmar que el aumento tolal de los medios de pago obedeció a un aumento en la expansión secundaria de dinero, particularmente porque los bancos estatales no cumplieron con sus obligaciones de encaje, lo que sí habian hecho en 1986.

En visla de lo anlerior, se puede sefialar que, al igual que El Salvador pero en un grado menor, el sislema bancario costarricense está padeciendo de una indisciplina, el cual redunda en un menor conlrol monelario de parte de las autoridades. Esta siluación imprime mayor inquielud al considerar que el diseño de polílica económica vigente en Costa Rica, es un lanto novedoso y por ende las autoridades se encuentran en una elapa relativamente temprana en la "curva de aprendizaje". Empero, la 
respuesta de las autoridades ha sido lo más oportuna posible y, en particular, se le ha permitido una intervención mayor a la superintendencia de bancos para tratar de solventar los actuales problemas bancarios.

En términos generales, la politica económica y sus normas en vigencia en 1987, posiblemente contribuyeron a atenuar lo que, en última instancia, bien hubiera sido un peligroso colapso financiero. Esto pudo haber ocurrido a pesar de varios años de penosos y dramáticos esfuerzos de estabilización. Consecuentemente, son estos magros resultados los que podrian llevar a cuestionar las políticas de liberalización (precipitada) tinanciera, que desde el punto de vista de un pais pobre en capital, bien podría carecer de senlido.

Las perspectivas para 1988 parten del hecho que en este afio entrará en vigencia un Convenio de Contingencia con el Fondo Monetario Internacional (FMI). Este convenio será la piedra angular para alcanzar las metas del programa económico y tinanciero, dentro de las cuales resalta a la visla la de reducir la tasa de inflación interna y mejorar la posición interna, con miras a crear las condiciones propicias para concretar un sólido proceso de reactivación económica.

Especificamente, las melas contemplan un crecimiento de la masa monelaria de $13.8 \%$, igual que el PIB nominal. Para lograr esle objetivo,

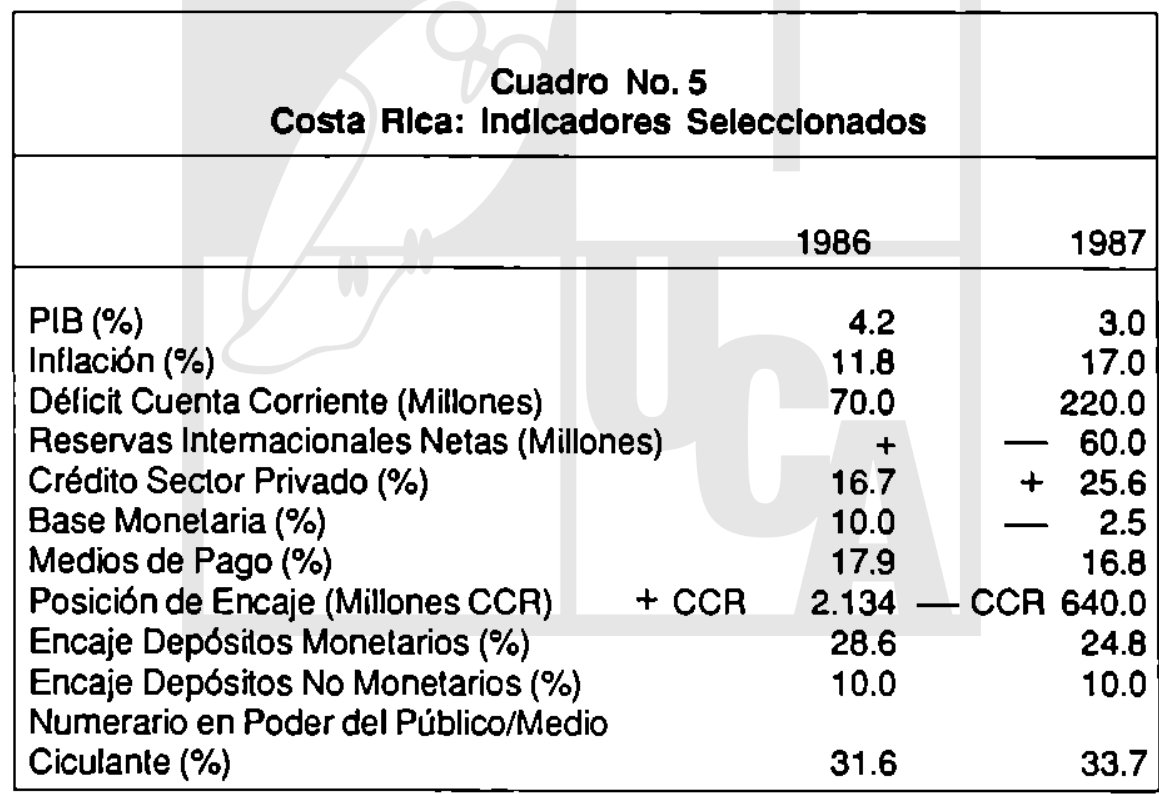

Fuenle: Banco Central de Cosla Rica 
se espera reducir el crédito neto al sector público no tinanciero en un $9.0 \%$ y al sector privado solamente se le permitirá un crecimiento del $9.3 \%$ en el crédilo nelo de parte del Banco Central. Como se puede apreciar, las autoridades monelarias piensan poner en práctica un plan económico mucho más restrictivo que en años anteriores, lo que significa un gran esfuerzo y el aporte de una alta cuola de sacrilicio por parte de todos los sectores económicos.

En resumen, los esluerzos internos realizados no han logrado superar la etapa de estabilización y ajuste. Ello bien podrla ser el resullado del nuevo modelo que se está tratando de instrumentar, para el cual se requiere un nuevo aparalo y diversos mecanismos que operen en los planos comercial y tinanciero. No se requiere de un extenso análisis para comprender que lo anterior involucra riesgos potenciales en cuanto a la expeclalivas de reanudación del proceso de desarrollo. Asl, la reciente precipitación de acontecimientos financieros incontrolables, parecerla justificar un examen crítico de lo logrado. No hay razones para creer, en eslos momentos, que un experimento económico como el que se está realizando, logre de inmediato reducir el nivel de incertidumbre que perciben los agentes económicos.

\section{Conclusiones}

En cuanto a los objetivos del programa de gobierno de un país, la política económica no se puede menoscabar como uno de los instrumentos más poderosos $\theta$ imprescindibles para lograrlos. El uso de la politica económica es un elemento fundamenlal para abrir nuevas fronteras y ampliar la cobertura de acción de un gobierno, como también para establecer ef liderazgo que exige el arte de gobernar. Desafortudamente, se puede generalizar que en Centroamérica, la política económica ha sido delegada a una función puramente pasiva y delensiva. Con todo ello, la crisis que afecta al área no justilica el poco o mal uso que se ha hecho de este instrumento.

Sin embargo, la acumulación de efectos derivados de la misma crisis, ha generado una "latiga" muy evidente en la instrumentación de la polltica económica. Lo anterior se manifiesta en diversos niveles.

De hecho, la conjugación de los aspectos monelarios y fiscales se ha visto desequilibrada por el exlenso uso que hicieran los paises con sus respectivas variables fiscales a principios de la década actual. A pesar de los logros actuales, en particular de Gualemala, los cuantiosos déficit públicos han obstaculizado la consecución de los objetivos buscados por la política monelaria y han conducido a una creciente interdependencia entre la política monelaria y las estralegias de financiamiento de los déficit públicos, que es luente de presiones no táciles de resolver. Por ejemplo, cuando los desajustes fiscales son cuantiosos y dura- 
deros, el cortrol monetario se debilita y puede incluso, hasla perder su función primordial, corno ha sucedido en Nicaragua.

Consecuentemente, en todos los paises la corrección de la problemática fiscal ha sido uno de los pivoles de los programas puestos en práctica. Asl, los esfuerzos para incrementar los ingresos se han concentrado principalmente en iniciativas de reformas tributarias (Guatemala, El Salvador, Costa Rica), cuyos resullados están aún por determinarse.

En lo que respecta a los egresos, se puede observar que la conIracción se ha concentrado en la inversión pública; asimismo, la voluntad de cumplir con el servicio de la deuda interna y externa ha impedido que se compriman aun más los egresos públicos. Estas contracciones han incurrido en acentuar los grandes sacrificios de índole político y social.

Por su parte, las presiones fiscales han incidido negativamente sobre la estructura de las tasas de Interés del mercado financiero interno. Dentro de los casos extremos, como el desquiciamiento financiero en Nicaragua, la poca disciplina financiera en El Salvador y el exceso de Imermediación financiera en Costa Rica, la incidencia negativa del déficil fiscal ha redundado en una acelerada expansión crediticia, la cual se ha activado como consecuencia de la predisposición de las entidades flnancieras a absober activos tinancieros de mayor riesgo.

De esta forma, existe una tendencia creciente en Cemroamérica que debilita la congruencia, en términos de rentabilidad y riesgo, entre los aclivos y pasivos de los respectivos sistemas bancarios. Como se sabe, lo anterior aumenta la probabilidad de insolvencia y de reliros masivos de depossitos y contribuye a que los niveles de las tasas de interés guarden una relación incoherente con otros precios claves de la economía, como por ejemplo el tipo de cambio.

Los desbalances bancarios y los desequilibrios fiscales explican en buena parte las presiones que acosan a los sistemas cambiarios de la región. En el contexto actual centroamericano, dicha presión es indicativa de distorsiones graves de los precios relalivos y de fallas de funcionamiento de los mercados, lo que se traduce en una pobre asignación de recursos que al mediano plazo desemboca en mayores distorsiones de los precios relativos y en un debilitamiento más agudo de la lormaclón de capital. Pero aún, la paridad del tipo de cambio tiende a quedarse rezagada debido al ambiente inflacionario, la incertidumbre politica y la lentitud institucional.

Aunque en algunos países se ha restiluido al tipo de cambio su función de ajuste, puede apreciarse una falla de uniformidad en los regimenes cambiarios de la región. Así, por ejemplo, en un pals, Costa Rica, el tipo de cambio se ha convertido en la principal variable de ajusle y en 
la piedra angular de su programa económico. En otros palses, las cuesliones cambiarias han sido colocadas en un pedestal, casi a la par de la mistica.

Empero, el tipo de cambio es un precio como cualquier otro $y$, consecuentente, está sujeto a las fuerzas económicas. Asi, pareciera que la instrumentación de la política económica ha hecho caso omiso de este detalle sencillo y en el camino se ha convertido en agenle activo de las presiones que azotan a los regímenes cambiarios.

\subsection{Rlesgo Camblario}

En vista de lo anterior, no se encuentran razones, salvo un ritmo mayor de donaciones en divisas, para no esperar, más temprano que tarde, una avalancha de modificaciones cambiarias a lo largo del Istmo. En otras palabras, el riesgo cambiario en la región ha alcanzado niveles muy elevados y es difícil que los mercados financieros mundiales inlenten asumir vualesquier tipo de riesgos por medio de un apoyo directo a la balanza de pagos via créditos u otros instrumentos.

La tendencia del riesgo cambiario puede ser evaluada por medio de diversos indicadores. En primer lugar, sobresale el indicador que se denomina "Diferencial inflacionario", el cual utiliza la relación entre la lasa de inflación intema y la tasa de inflación externa para obtener elementos de juicio al respecto. Así, para Centroamérica se tiene:

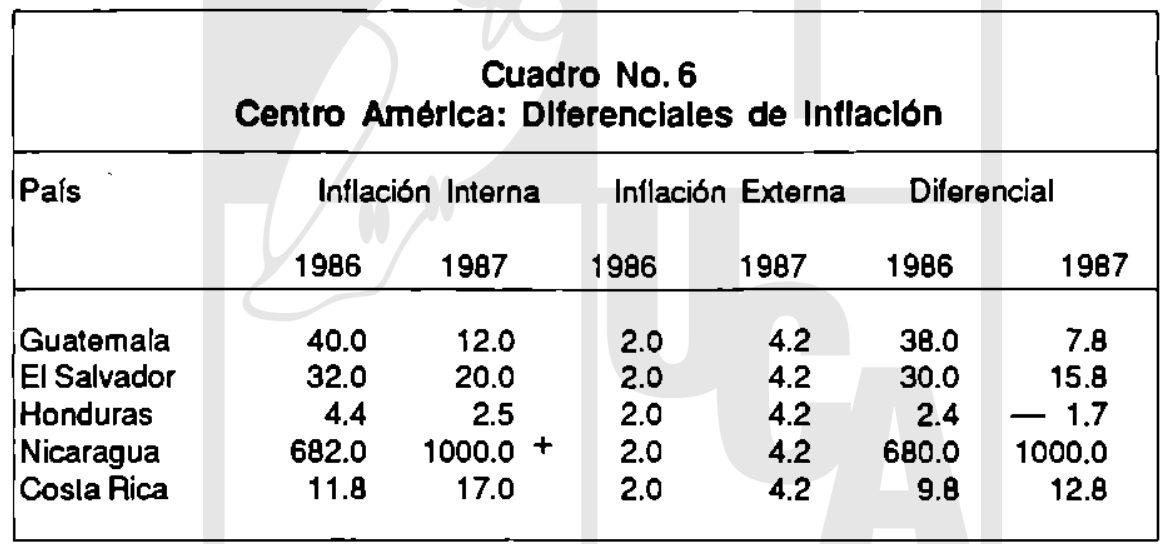

Como se puede observar, tres paises lograron reducir el diferencial en 1987 y, entre ellos, el caso de Honduras es insólito ya que dicho diferencial se sitúa a un nivel negativo. Dentro de los países en los cuales el diferencial aumentó, continúa siendo preocupante el caso de Nicaragua. Por su parte, el deterioro del diferencial en Costa Rica es debido prin- 
cipalmeme a presiones financieras y cambiarias que alimentaron el proceso inflacionario. Sin embargo, la autoridad monetaria costarricense aprobó a principios de 1988 una devaluación del 6.0\% para contrarrestar las mismas.

En cuanto al riesgo cambiario, es menester sefialar que tres países (El Salvador, Honduras y Cosla Rica) han logrado cuadrar sus balanzas de pagos en base a transierencias unilaterales oficiales, las cuales no responden a las fuerzas del mercado. De esta lorma, no se debe hacer caso omiso del hecho que, en eslos tres paises, el factor estabilizante más importante del tipo de cambio es un factor exógeno que nada, o muy poco liene que ver con la dirección y congruencia de la política económica. Asimismo, no se debe esperar que este facior continúe ejerciendo dicha función eternamenle $y$, consecuentemente, cuando esto suceda, un elemento esencial de la política económica será la modificación cambiaria.

En resumen, el riesgo cambiario es un componente ineludible del panorama económico centroamericano. En primer lugar, con la excepción de Honduras y a pesar del mejoramiento del diterencial inflacionario en otros dos países, dicho indicador se sitúa aclualmente a niveles superiores a los que prevalecieron en las dos décadas anteriores. En segundo término, los rubros extra-económicos de la balanza de pagos juegan en la actualidad un papel de válvula de escape ante los desequilibrios que aquejan al sector externo. Así pues, a pesar de los drásticos ajustes que han experimentado las balanzas de pagos de los países del área -una especie de sesgo anlirregional ya que el ajusle económico realizado por los paises del área ha tenido un impacto desproporcional sobre el comercio intrarregional- el proceso correctivo que ejercen los precios relativos y el ingreso, está aún por completarse, lo que indica que el riesgo cambiario continúa latente y amenazanle.

Como se habrá podido colegir, el riesgo cambiario se origina fundamentalmente en el uso indebido de los inslrumentos de política económica. En un grado menor, figuran las variaciones inesperadas en los términos de inlercambio y lambién, la polílica económica del pais cuya moneda es utilizada como medio de reserva internacional. Sin embargo, el empleo de la política económica en forma oporluna puede neutralizar los efectos a largo plazo de eslos dos faclores. Consecuentemente, es en la instrumentación y en la congruencia de la política económica donde se debe comenzar a indagar lodo lo tocante al riesgo cambiario.

Así, el desencaje enlre el produclo y el ingreso, resullante casi siempre de la mala aplicación de la política económica, se traduce en un exceso de demanda, la cual desemboca en un incremento en las imporlaciones; por su parte, la sobrevaluación de la moneda, siluación 
perenne en Centroamérica, también ejerce el mismo efecto sobre las importaciones. Estos electos tienen un impacto adverso sobre la cuenta corriente de la balanza de pagos.

En ese órden de ideas, la falla de congruencia entre las cuentas ftscales y monetarias, también producto del uso incorrecto de los instrumentos de política económica, impacta negativamente a la cuenta de capital de la balanza de pagos. En primer lugar, agiliza lo que comunmente se llama "fuga de capital" $y$, en segundo lugar, tlende a desincentivar la inversión directa externa ya que crea un diferenclal mayor en la rentabilidad entre los activos internos y los activos extemos.

En general, bs impactos desfavorables de la politica económica 80 manifiestan tanto en la cuenta corriente como también en la cuenta de capital, lo que redunda en una fuerte lendencia hacia la disminución del ace vo de reservas internacionales. Esta tendencia es el otro lado de la $\pi$ ’da del riesgo cambiario.

in cuanto al riesgo cambiario y por ende al comportamiento de las res rvas internacionales, no se puede omitir el efecto negativo que eman. e la problemática de la deuda externa. Los palses de la región han desplegado sendos esluerzos para cumplirla y asi mantener un saludar' 9 "slatus" crediticio. Sin embargo, el peso de la deuda abruma a los cin s palses $y$, en particular, enlorpece el manejo de sus respectivas po' 'icas económicas. A la luz de ello, el servicio de la deuda extema ha $\|_{l}$ :do a convertirse en otro elemento clave en la determinación del riesgo cambiario.

r'or su parte, con el propósito de hacer compatible el ajuste y la reaclivación, los paises del área han tratado de incrementar y diversiticar sus exportaciones. Sin embargo, las resultados no han sido muy fructiferos. La experiencia de otros palses ha demostrado que sin incrementos en las exportaciones, el servicio de la deuda, bajo las condiciones actuales, liene una relación inversa con el crecimiento económico. Asl, el serviclo de la deuda aunado a los esfuerzos regionales de establlización econó sa, redundarán en un elevado sacrilicio de la inversión y del freno de la producción. He aqui un aspecto adicional para no esperar un decremento en el nivel de riesgo cambiario. 